\title{
NAVIGATED VERSUS MECHANICAL KNEE REPLACEMENT: COMPARISON BETWEEN INITIAL NAVIGATED AND CONVENTIONAL CASES PERFORMED BY THE SAME SURGEON
}

\author{
Alexandre Pagotto Pacheco', Oswaldo Taglietta Filho', Roberto Freire da Mota e Albuquerque ${ }^{2}$, Alessandra Cristina Brambilla ${ }^{3}$
}

\section{ABSTRACT}

Objective: The postoperative mechanical axis in 36 cases of total knee arthroplasty using navigated and mechanical alignment systems was evaluated and compared. All the operations were performed over the same period by the same surgeon and team, who were beginners in the navigated technique and experienced in the mechanical technique. Methods: Between 2008 and 2010, 36 total knee prostheses were performed and compared: 25 navigated and 11 mechanical procedures. Any deviation from the axis measured on the panoramic postoperative X-ray was considered positive. Results: The navigated prostheses produced a mean axis deviation of 1.32 degrees and standard deviation of 1.57 degrees and the mechanical, respectively 3.18 and 2.99 degrees. There was better alignment with a tendency towards a statistical difference favoring the navigated technique. Conclusion: There were significantly more cases with axis deviation greater than three degrees using the mechanical technique. The navigated technique was incorporated by this team without additional complications and, even without experience of navigated surgery, the initial cases achieved better alignment than with the mechanical technique, and a significantly smaller number of outliers from the three-degree safety zone.

Keywords - Knee; Arthroplasty; Surgery, Computer-Assisted

\section{INTRODUCTION}

Total arthroplasty is greatly used in cases of advanced osteoarthrosis of the knee with the aims of eliminating painful symptoms, correcting deformities and stabilizing the joint. The success of the surgical procedure depends on several factors, such as patient selection, prosthesis design, ligament balance and restoration of the knee joint line and lower-limb alignment ${ }^{(1-8)}$.

Restoration of limb alignment is believed to be one of the principal factors enabling good long-term results, both clinically and functionally. Varus or valgus deviation of more than three degrees from the mechanical axis is associated with lower rates of functional satisfaction and poor results ${ }^{(2-4,9-12)}$. A significant percentage of misalignment from the mechanical axis may occur in spite of the surgeon's experience with mechanical prostheses ${ }^{(13)}$.
Over recent years, computer-assisted surgical systems have contributed towards surgical precision. According to Albuquerque et $\mathrm{al}^{(1,14)}$, the main contribution of such systems is precision in implanting prostheses and aligning the mechanical axis of the operated limb. Furthermore, such procedures are little more invasive; they diminish or eliminate exposure to radiation; and the instruments used are the same as used in mechanical procedures. This last point means that the technique can be changes without compromising the procedure.

Comparisons between navigated surgery and the conventional method ${ }^{(4,6,9,15-17)}$ have demonstrated that computer-assisted surgery may provide better alignment in the coronal and sagittal planes (less than three degrees from neutral alignment), since it helps the surgeon to determine the alignment throughout

1 - Orthopedist and Subspecialist in Knee Surgery, Piracicaba, SP, Brazil.

2 - Attending Physician in the Knee Group, Institute of Orthopedics and Traumatology, HC/FMUSP, São Paulo, SP, Brazil.

3 - Physiotherapist at Safe Institute, Piracicaba, SP, Brazil.

Work performed at the Sugarcane Suppliers' Hospital, Piracicaba, SP.

Correspondence: Travessa João José Abdalla 436/52, 13417-431 Piracicaba, SP. E-mail: alexpacheco@terra.com.br

Work received for publication: June 27, 2011; accepted for publication: September 12, 2011.

The authors declare that there was no conflict of interest in conducting this work 
the operation. Factors weighing against adoption of the navigation technique by teams that are already experienced in the mechanical technique include variables such as the learning curve, increased duration of the operation and associated morbidity ${ }^{(1,4,9)}$.

\section{OBJECTIVE}

To evaluate and compare the postoperative mechanical axis in cases of total knee arthroplasty using navigated and mechanical alignment systems, performed by a surgeon who was a beginner in the navigated technique.

\section{MATERIAL AND METHOD}

Between 2008 and 2010, 36 total knee prostheses were implanted in 31 individuals, comprising 12 men and 19 women of mean age 71 years (range: 53 to 85 years), and were subsequently evaluated. Five individuals underwent the procedure bilaterally. Twenty-five cases were operated using the navigated technique and 11 using the mechanical technique. For the navigated prostheses, the model of the French company Amplitude was used, with its Amplivision navigation system. The model for the mechanical prosthesis was the Brazilian Modular III, made by the company MDT (in nine cases) and the Advance Medial Pivot model of the American company Wright (in two cases).

All the patients had a previous history of knee osteoarthritis and were assessed at least six months after the surgical procedure. In all the operations, the posterior cruciate ligament was sacrificed, and in none of them was the patella replaced. All the cases with a mechanical prosthesis were planned by measuring the physiological valgus of the femur on a digital panoramic radiograph. This was then applied to the distal femoral cut. The cuts were made using an intramedullary alignment guide on the femur and tibia. No degree of varus or valgus deformity of the mechanical axis was grounds for exclusion. The cases were chosen randomly insofar as when the economic and healthcare conditions and the size according to the template trials allowed, the navigated technique was always chosen. For the other cases, mechanical prostheses were used. All the operations were performed by the same surgeon and the same team, composed of one auxiliary physician, two instrument operators and one navigation operator. The surgeon had had 10 years of practical experience of arthroplasties and had had contact with and had studied the technique, but had never performed a navigated arthroplasty. The team had been working together for eight years.

After the operation, frontal digital panoramic radiographs were produced with weight-bearing on the operated limb, and the mechanical axes were measured. Any valgus and varus deviations encountered were noted. Both valgus and varus deviations were taken into consideration and the numbers were always taken to be positive. The mechanical axes and the deviations were determined on radiographs by an independent evaluator who did not have any knowledge about the visual differences among the prostheses.

In the statistical analysis, it was found that the variables did not meet the criteria of normal distribution for comparisons between the samples. Thus, the Wilcoxon test for independent samples was used. The results outside of the three-degree safety zone (i.e. outliers) were also analyzed and were subjected to Fisher's exact test. The significance level was taken to be $p<0.05$.

\section{RESULTS}

The mean deviation from the axis achieved with the navigated prostheses was 1.32 degree, with a standard deviation of 1.57 degrees. The mean for the mechanical prostheses was 3.18 degrees, with a standard deviation of 2.99 degrees (Table 1). The non-parametric comparison found $\mathrm{p}=0.0891$ (Table 2). This was not a statistical difference, but it showed a tendency towards a statistical difference, which might have been observed if the number of cases had been greater. Regarding the number of cases outside of the three-degree safety zone (outliers), there were six cases among the 11 with the conventional procedure and only two cases among the 25 navigated cases, thus presenting a highly significant difference with $\mathrm{p}=0.005$ (Table 3).

\section{DISCUSSION}

There has been much discussion about the value of changing to the navigation technique in cases of total knee arthroplasty operated by trained teams. We have sought to help to clarify this through the initial cases conducted by a surgeon with personal experience of 
Table 1 - Deviations obtained.

\begin{tabular}{|c|c|}
\hline \multicolumn{2}{|c|}{ Deviation seen on postoperative radiograph } \\
\hline Navigated & Mechanical \\
\hline 0 & 5 \\
\hline 0 & 5 \\
\hline 2 & 0 \\
\hline 0 & 6 \\
\hline 3 & 4 \\
\hline 0 & 1 \\
\hline 0 & 4 \\
\hline 1 & 9 \\
\hline 1 & 0 \\
\hline 2 & 1 \\
\hline 0 & 0 \\
\hline 4 & 3.18 \\
\hline 0 & 2.99 \\
\hline 6 & \\
\hline 0 & \\
\hline 0 & \\
\hline 1 & \\
\hline 2 & \\
\hline 0 & \\
\hline 0 & \\
\hline 3 & \\
\hline 3 & \\
\hline 2 & \\
\hline 2 & \\
\hline 1 & \\
\hline 1.32 & \\
\hline 1.57 & \\
\hline
\end{tabular}

Table 2 - Statistics on deviations.

\begin{tabular}{|c|c|c|}
\hline \multicolumn{3}{|c|}{ Normality } \\
\hline Results & Navigated & Mechanical \\
\hline Sample size & 25 & 11 \\
\hline Mean & 1.3200 & 3.1818 \\
\hline Standard deviation & 1.5737 & 2.9939 \\
\hline$W$ & 0.8131 & 0.8916 \\
\hline $\mathrm{p}$ & 0.0092 & 0.1978 \\
\hline & Normal & N Normal \\
\hline \multicolumn{3}{|c|}{ Nonparametric comparison } \\
\hline Results & Navigated & Mechanical \\
\hline Sample size & 25 & 11 \\
\hline Sum of posts $(\mathrm{Ri})$ & 413.0 & 253.0 \\
\hline Median & 1.00 & 4.00 \\
\hline $\mathrm{U}$ & 88.00 & \\
\hline$Z(U)$ & 1.6999 & \\
\hline $\mathrm{p}$-value (unilateral) & 0.0446 & \\
\hline p-value (bilateral) & 0.0891 & \\
\hline
\end{tabular}

Tendency towards a statistical difference.

Table 3 - Statistics on the outliers.

\begin{tabular}{c|c|c|c}
\hline \multicolumn{3}{|c|}{ Fisher's exact test } & Outliers \\
\hline & \multicolumn{2}{|c}{ Three-degree safety zone } \\
\hline & Outside & Inside & Total \\
\hline Mechanical & 6 & 5 & 11 \\
\hline Navigated & 2 & 23 & 25 \\
\hline & & & $\mathrm{p}=0.005$ \\
\hline & $\mathrm{X}^{2}=7.0071$ & & \multicolumn{2}{c}{}
\end{tabular}

between 200 and 300 arthroplasties. There had been adequate training on the navigated technique, but no practice on it.

Although we did not calculate the duration of the operation, the increase in the time taken with navigation was not discouraging. In no case was there a need to deflate the tourniquet until cementation of the implants. These findings are concordant with the descriptions by Albuquerque ${ }^{(1)}$, Bäthis et $\mathrm{al}^{(4)}$ and Cheung and $\mathrm{Chiu}^{(9)}$, who stated that the increase duration of the procedure did not have any decisive influence on the final result. However, it is worth emphasizing that a good team is required for performing this technique. Our team had an auxiliary surgeon who was also a subspecialist on knees, two instrument operators and one navigation operator. Furthermore, we did not replace the patella and we cemented the components in a single procedure. Without this group, there might have been an increase in the duration of the operation, and perhaps greater morbidity.

The criterion for choosing the prosthesis in our cases was not according to technical difficulty. There were simple and challenging cases in both groups. It was sought to minimize alignment errors with the mechanical technique, by calculating the anatomical valgus of the femur case by case, using digital radiographs, in the same way as done by Bäthis et $\mathrm{al}^{(4)}$ and Pang et $\mathrm{al}^{(16)}$, who achieved some of the best alignments among cases with mechanical prostheses in the comparative studies surveyed. Among the navigated cases, we had a learning curve, especially because it often happened that many of the parameters offered were not greatly made use of. It is likely that, with increasing experience, the results from navigated cases should improve.

The prostheses for the navigated and non-navigated cases had different origins. Therefore, the measurement and cutting instruments could have an influence, which might represent a further variable that should be taken into consideration as possible influences on the final result. However, we believe that each system was developed for maximum precision regarding measurements, and that we extracted the best from each of these. Moreover, the orientation of the bone cuts only has a relationship with the instruments used for positioning the cutting guides. Thus, comparison of the cuts made with and without a navigation system does not depend on the make and model of the prostheses 
used. Obviously, the results may vary as a function of the navigation system and conventional guides used, and thus, the results should be given value within this context, just as in other comparative studies ${ }^{(9,15,16)}$.

The sample was not large, but it was sufficient to show a real difference in the means and standard deviations between the techniques, with a tendency towards a statistical difference, even though this did not actually exist. On the other hand, the outliers calculation was highly statistically significant, showing the cases that went outside of the safety zone of three degrees of deviation, which was the central aim of our efforts towards aligning the arthroplasties as well as possible. This parameter is widely used in the literature ${ }^{(2-4,6,9-12,14-17)}$. It is worth noting that the surgeon and auxiliary surgeon, between them, had experience of around 500 mechanical prostheses, while these were their first cases of navigated prostheses. Even so, the navigated prostheses achieved smaller deviations from the axis.

Comparing our results with the literature that we surveyed ${ }^{(4,6,9,15-17)}$, shown here between parentheses, we obtained a mean of 1.32 degrees $(0.4$ to 1.9$)$ of deviation from the axis with the navigated prostheses and 3.18 (1.0 to 4.2) with the mechanical prostheses.
Regarding the percentage of outliers, we achieved $8 \%$ ( 0 to $22 \%$ ) for the navigated prostheses, and 55\% (13 to $57 \%$ ) for the mechanical prostheses. We did not find any discordance with the literature, which indicated conclusions similar to ours.

During the postoperative period and the first months after the surgery, we did not observe that one technique was superior to the other in terms of function or subjective satisfaction.

\section{CONCLUSIONS}

The technique of arthroplasty by means of navigation was incorporated by our team without additional complications.

Even without practical experience in navigated surgery, the first cases achieved better alignment than with the mechanical technique, with a tendency towards a statistical difference.

There were fewer cases with deviation of more than three degrees (the safety zone) from the mechanical axis, when the navigated technique was used, and this was highly statistically significant.

We obtained results that were comparable to those in the literature.

\section{REFERÊNCIAS}

1. Albuquerque RFM. Navegação na artroplastia total do joelho. Rev Bras Ortop. 2011;46(1):18-22.

2. Dorr LD, Boiardo RA. Technical considerations in total knee arthroplasty. Clin Orthop Relat Res. 1986;(205):5-11.

3. Ritter MA, Faris PM, Keating EM, Meding JB. Postoperative alignment of total knee replacement. Its effect on survival. Clin Orthop Relat Res. 1994;(299):153-6.

4. Bäthis $H$, Perlick L, Tingart M, Lüring C, Zurakowski D, Grifka J. Alignment in total knee arthroplasty. A comparison of computer-assisted surgery with the conventional technique. J Bone Joint Surg Br. 2004;86(5):682-7.

5. Delp SL, Stulberg SD, Davies B, Picard F, Leitner F. Computer assisted knee replacement. Clin Orthop Relat Res. 1998;(354):49-56.

6. Sparmann M, Wolke B, Czupalla H, Banzer D, Zink A. Positioning of total knee arthroplasty with and without navigation support. A prospective, randomised study. J Bone Joint Surg Br. 2003;85(6):830-5.

7. Kumar PJ, Dorr LD. Severe malalignment and soft-tissue imbalance in total knee arthroplasty. Am J Knee Surg. 1997;10(1):36-41.

8. Wasielewski RC, Galante JO, Leighty RM, Natarajan RN, Rosenberg AG. Wear patterns on retrieved polyethylene tibial inserts and their relationship to technical considerations during total knee arthroplasty. Clin Orthop Relat Res. 1994;(299):31-43.

9. Cheung $\mathrm{KW}$, Chiu $\mathrm{KH}$. Imageless computer navigation in total knee arthroplasty. Hong Kong Med J. 2009;15(5):353-8
10. Petersen TL, Engh GA. Radiographic assessment of knee alignment after total knee arthroplasty. J Arthroplasty. 1988;3(1):67-72.

11. Jeffery RS, Morris RW, Denham RA. Coronal alignment after total knee replacement. J Bone Joint Surg Br. 1991;73(5):709-14.

12. Fuchs R, Matuella F, Rabello LT.Artroplastia total do joelho. Avaliação a médio prazo: dois a dez anos. Rev Bras Ortop. 2000;35(2):94-101.

13. Mahaluxmivala J, Bankes MJ, Nicolai P, Aldam CH, Allen PW. The effect of surgeon experience on component positioning in 673 Press Fit Condylar osterior cruciate-sacrificing total knee arthroplasties. J Arthroplasty. 2001;16(5):635-40.

14. Albuquerque RFM, Angelini FJ, Pécora JR, Amatuzzi MM, Sasaki SU. Artroplastia total do joelho assistida por computador Acta Ortop Bras. 2006;14(4):199-202.

15. Ek ET, Dowsey MM, Tse LF, Riazi A, Love BR, Stoney JD, Choong PF. Comparison of functional and radiological outcomes after computer-assisted versus conventional total knee arthroplasty: a matched-control retrospective study. J Orthop Surg (Hong Kong). 2008;16(2):192-6.

16. Pang $\mathrm{CH}$, Chan WL, Yen $\mathrm{CH}$, Cheng SC, Woo SB, Choi ST, et al. Comparison of total knee arthroplasty using computer-assisted navigation versus conventional guiding systems: a prospective study. J Orthop Surg (Hong Kong). 2009;17(2):170-3.

17. Blakeney WG, Khan RJ, Wall SJ. Computer-assisted techniques versus conventional guides for component alignment in total knee arthroplasty: a randomized controlled trial. J Bone Joint Surg Am. 201;93(15):1377-84. 